\title{
曲がりダクトによるターボ機械内部流れの損失生成機構の解明*
}

(第 3 報，曲がり角の影響）

$$
\text { 辻田星歩*1, 水木新 平*1, 山本孝 正*2 }
$$

\section{Investigation for Loss Generation Mechanisms of Flow in Turbomachinery by Using Curved Square Duct (3rd Report, Influence of Curved Angle)}

\author{
Hoshio TSUJITA*3, Shimpei MIZUKI and Atsumasa YAMAMOTO \\ ${ }^{* 3}$ Department of Mechanical Engineering, Hosei University, \\ 3-7-2 Kajino-cho, Koganei-shi, Tokyo, 184-8584 Japan
}

\begin{abstract}
In a series of present studies, the flows within the stationary curved ducts are analyzed numerically with the aerodynamic or the geometrical parameters affecting the loss generation caused by the passage vortex within a passage of a turbomachinery. In the former reports, the inlet boundary layer thickness and the inlet velocity distortion were taken as the aerodynamic parameter and the aspect ratio of the cross-section was chosen as the geometrical parameter. In this report, the effects of the curved angle of the bend on the loss generation caused by the passage vortex are examined by relating the bend of curved duct to the blade-to-blade surface of an axial flow turbine cascade. The curved angle is changed from 90 to 160 degree by 10 degree with fixing the length of arc for the mean radius of curvature of the bend or fixing the mean radius of curvature.
\end{abstract}

Key Words: Turbomachinery, Secondary Flow, Numerical Analysis, Loss Generation, Passage Vortex, Curved Duct, Curved Angle

\section{1. 緒 論}

ターボ形流体機械の羽根車流路内の流れの損失生 成は，馬蹄形渦，流路渦およひ翼端屚孔渦等の二次流 れに強く影響を受け，その中でも特に流路渦の寄与す るところが大きい，流路渦が発生する基本的なモデル 流路は曲がりダクトである. 本研究は実機のターボ機 械流路内で発生する流路渦の形成に影響を与える流体 力学的パラメータや翼列の幾何学的パラメータを, 静 止曲がりダクト内の流れに対して変化させて数值解析 を行い，流路渦と損失発生の関係を解明することを目 的としている. 曲がりダクトは実機の翼列に比べ形状 が簡単なため, 直交性の良い計算格子の使用が可能と なり, その内部流れを対象にした数值解析結果の信頼 性も高い：また，本研究は現段階では実機の羽根車内 の流れの損失生成に影響を与えうる Mach 数や㣫撃 波と境界層の干涉を除外し, 流路渦に起因寸る損失生 成にのみ着目しているため, 実機に比べると比較的低

* 原稿受付 2004 年 7 月 22 日.

*1 正員, 法政大学工学部 (严 184-8584 小金井市梶野町 3-7-2).

*2 正員, 宇宙航空研究開発機構航空宇宙技術研究七ン夕ー ( 182-8522 調布市深大寺東町 7-44-1).

E-mail : tsujita@ k.hosei.ac.jp
い Reynolds 数および Mach 数の流れを対象にしてい る. 第 1 報(1) では本数值解析法の計算精度を検証した 上で, 流体力学的パラメータである入口境界層厚さと 入口速度分布の不均一性を変化させ, 第 2 報(2) では幾 何学的パラメータの一つである断面のアスペクト比を 変化させて解析を行い，それらのパラメータによる流 路渦の形成およひ損失生成に与える影響について解明 した. 本報では以下のような観点から曲がりダクトの 曲がり角の影響に着目した.

近年, ガスタービンの性能向上を目的に, タービン 翼の高負荷化に関する研究(3) (5)が行われているが, 高負荷化に伴い転向角が増大し, 翼間流路内での圧力 勾配が大きくなるため，流路渦などを含む二次流れが

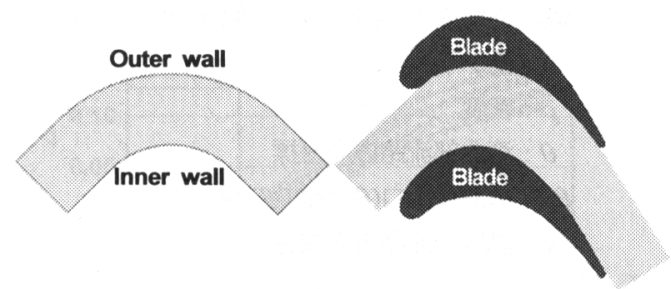

(a) Curved duct $\quad$ (b) Axial flow turbine cascade Fig.1 Correspondence of curved duct to axial flow turbine cascade 
強く発生し, 翼列性能が劣化する傾向にある. したが って，性能を少化させることなく高負荷化を実現する には，転向角による流路渦の形成およひ損失生成への 影響を解明することが重要である.そこで特に曲がり ダクトの湾曲部形状を軸流タービン翼列の翼間面と関 連付け(図 1), 曲がりダクトの曲がり角を翼列の幾何 学的パラメータである転向角に対応させて変化させ, その内部流れの数值解析を行い, 曲がり角が流路渦の 形成および損失生成に与える影響について解明した.

\section{2.おもな 記 号}

$A_{c p s}:$ 湾曲部での内外壁面間の圧力差

$C_{p s}:$ 静圧係数 $=\left(p-p_{\text {ref }}\right)\left(\rho V_{c}^{2 / 2}\right)$

$C_{p t}:$ 全圧損失係数 $=\left(p_{t r e f}-p\right) /\left(\rho V_{c}^{2} / 2\right)$

$D:$ 水力直径

$H:$ ダクト高さ

$L_{c}: R_{c}$ に対する湾曲部長さ $=2 R_{c} \pi \alpha / 360$

$L_{R}$ : 幾何形状表示用代表長さ $(=0.04 \mathrm{~m})$

$p$ : 静圧

$p_{t}:$ 全圧

$p_{\text {ref }}:$ 基淮静圧 $\left(\theta=0^{\circ}, r^{*}=Z^{*}=0\right.$ での静圧 $)$

$p_{\text {tref }}$ : 基準全圧(ダクト入口断面質量平均全圧)

$Q:$ 体積流量

$R_{a}:$ 断面アスペクト比 $=S / H$

$R_{c}$ : 平均曲率半径 $=0.5\left(r_{i}+r_{o}\right)$

$R_{e}:$ Reynolds 数 $=\rho D V_{c} / \mu$

$r_{i}:$ 内壁の曲率半径

$r_{o}:$ 外壁の曲率半径

$S:$ ダクト幅

$V_{c}:$ 断面平均流速

$X_{h}: \theta=0^{\circ}$ を原点とする $L_{R}$ で無次元化した 流路方向距離

$X D: \theta=\alpha$ を原点とする $L_{R}$ て無次元化した 流路方向距離

$Z:$ :゙クト幅方向の座標

$Z^{*}$ : ダクト幅中央を原点とする $S / 2$ で無次元 化したダクト幅方向距離

$\Delta C_{p t}:$ 流路渦に起因寸る全圧損失係数

$\Delta \theta_{y}$ : 湾曲部出口 $(\theta=\alpha)$ での偏向角 $\left(=\theta_{y}-\alpha\right)$

$\alpha:$ 曲がり角

$\rho:$ 密度

$\theta:$ 湾曲部流路方向座標

$\theta_{y}:$ 湾曲部出口 $(\theta=\alpha)$ での流出角

$\omega_{i}:$ 渦度の流路方向成分

添 字

,i：断面質量平均値 ,ij : ダクト高さ $H(\mathrm{k})$ 方向質量平均値

,ik : ダクト幅 $S(\mathrm{j})$ 方向質量平均值

\section{3. 数值解析法}

本数值解析法は, 標準の $k \varepsilon$ モデルを含む物理成分 テンソル形で表わした定常非纴縮性乱流に対する基整 方程式を用いている. 式の離散化には有限体積法を, 対流項の評価には三次風上差分法を用いた. 計算のア ルゴリズムは SIMPLE 法である. 詳細は文献(6)と(7) に示されている. また，本解析法による計算精度は第 1 報(1)において検証済みである.

\section{4. 曲がりダクトの形状}

図 2 に本研究の解析対象となる曲がり角かが $90^{\circ}$ の 場合の曲がりダクトを示す. 本研究では表 1 に示す断 面積の等しい断面アスペクト比 $R_{d}(=S / H)$ が 10 と 3.0 の 2 種類の断面形状を有するダクトを対象に解析を行 った.この 2 種類の断面形状は，第 2 報(2)において $R_{a}$ の流路渦に起因する損失生成への影響を調べた際 に, $R_{a}=2.0$ を境にそれ以下になると急激に流路渦に 起因する損失生成が増加することが示されたため，そ の前後の值のアスペクト比として選んだ. さらに, こ れらの 2 種類の断面形状のダクトに対して，図 3 およ び表 2 に示すように $\alpha=90^{\circ}$ ，平均曲率半径 $R_{c}=0.092 \mathrm{~m}$ および弯曲部長さ $L_{c}=0.145 \mathrm{~m}$ の曲がり ダクトを基淮にし， $L_{c}$ または $R_{c}$ を固定して $\alpha$ を $90^{\circ}$ から $160^{\circ}$ まで $10^{\circ}$ 毎に変化させた合計 30 種類の曲 がりダクト内の流れの解析を行った. 曲がり角 $\alpha$ を增 加させると運動量の定理から翼列の負荷に関係づけら れるダクト湾曲部分に作用する力は増加する. 基淮曲 がりダクトに対し， $L_{c}$ を固定して $\alpha$ を増加させると壁 面摩擦損失の増加は抑えられるが， $\boldsymbol{R}_{\boldsymbol{c}}$ が減少するた め流路渦が強くなり，それによる損失生成が増加する. 一方， $\boldsymbol{R}_{\boldsymbol{c}}$ を固定して $\alpha$ を増加させると，流路渦による 損失生成の増加は抑えられるが， $L_{c}$ が増加するため 壁面摩摖損失が増加する.

\section{5. 結果および考察}

解析対象となる全ての曲がりダクトに対し，入口境 界条件として主流方向に断面平均流速 $V_{c}=1.0 \mathrm{~m} / \mathrm{s}$ の 一様速度分布を与えることにより，流量は $Q=1.6 \times$ $10^{-3} \mathrm{~m} / \mathrm{s}$ に固定した. また, 上流側の直線ダクトの 長さ $L_{U}$ と下流側の直線ダクトの長さ $L_{D}$ (図 2)は各々 $3.75 L_{R}$ と $7.5 L_{R}$ に設定した. ここで， $L_{R}$ は幾何学的

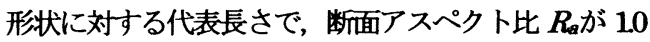
のダクトの水力直径 $D=0.04 \mathrm{~m})$ とする. 計算格子の数 は $R_{a}=1.0$ の基淮曲がりダクトに対しては95(流路方 


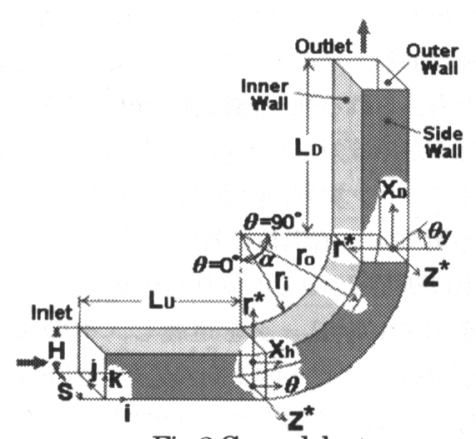

Fig.2 Curved duct

Table 1 Parameters depending on $R_{a}$

\begin{tabular}{|c|c|c|c|c|}
\hline$R_{\mathrm{a}}$ & $H(m)$ & $D(m)$ & $R_{\mathrm{e}}$ & $\mathrm{Q}\left(\mathrm{m}^{3} / \mathrm{s}\right)$ \\
\hline 1.0 & 0.040 & 0.040 & 40000 & 1.60 \\
\cline { 1 - 4 } 3.0 & 0.023 & 0.035 & 34263 & $\mathrm{\times} 10^{-3}$ \\
\hline
\end{tabular}

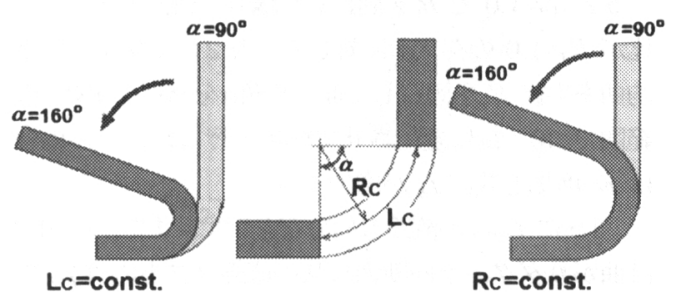

Fig.3 Variation of curved angle

Table 2 Geometrical parameters

\begin{tabular}{|c|c|c|c|c|}
\hline \multirow{2}{*}{$\alpha(\mathrm{deg})$} & \multicolumn{2}{|c|}{$L_{c}=$ const. } & \multicolumn{2}{|c|}{$R_{c}=$ const. } \\
\hline & $L_{d}(m)$ & $R_{d}(m)$ & $L_{d}(m)$ & $R_{c}(\mathrm{~m})$ \\
\hline 90 & \multirow{8}{*}{0.145} & 0.092 & 0.145 & \multirow{8}{*}{0.092} \\
\hline 100 & & 0.0828 & 0.161 & \\
\hline 110 & & 0.0753 & 0.177 & \\
\hline 120 & & 0.0690 & 0.193 & \\
\hline 130 & & 0.0637 & 0.209 & \\
\hline 140 & & 0.0591 & 0.225 & \\
\hline 150 & & 0.0552 & 0.241 & \\
\hline 160 & & 0.0518 & 0.257 & \\
\hline
\end{tabular}

向 $) \times 35(H$ 方向 $) \times 35(S$ 方向 $)$ であり, $R_{a}=3.0$ のダクト の場合は断面内の格子数を $27(H$ 方向 $) \times 55(S$ 方向 $)$ に 設定し, また， $R_{c}$ 固定の場合は $\alpha$ の増加に伴い 流路方 向の格子数を最大 115 まで増やした.

5.1 $R_{a}=1.0$ で $L_{c}$ 固定の場合 断面アスペクト比が $R_{a}=1.0$ のダクトに対して, 表 2 に示すように湾曲部 長さ $L_{c}$ を固定して曲がり角 $\alpha$ を $90^{\circ} \sim 160^{\circ}$ の範用で $10^{\circ}$ 毎に変化させて解析を行った. この場合は $\alpha$ の増 加と共に $R_{c}$ が減少する.
図 4 に全圧損失係数 $C_{p t}$ の断面質量平均值 $C_{p t, i}$ の流 路方向分布を湾曲部(以下 $\mathrm{CD}$ と略す)入口 $\left(X_{h}=0\right)$ での 值を基淮に示寸. 図 4 中の $X_{h}$ は CD 入口 $\left(\theta=0^{\circ}\right)$ を原 点とする $L_{R}$ で無次元化したダクト断面中央位置での 流路方向の距離である(図 2). また, 同図には曲がり ダクトと同じ断面形状を有する直線ダクト内の流れを 曲がりダクトと同一入口境界条件のもとに解析した結 果から得られた $C_{p t, i}$ の分布を実線で示寸. 直線ダクト $C_{p t, i}$ の分布はダクトを構成する 4 つの壁面上での境界 層発達に起因する損失生成を示している. 図 4 力ら $\alpha$ の増加に伴い全圧損失 $C_{p t, i}$ が増加するとどわかる. 次 に，流路渦に起因する損失生成に対する 0 影響を調 ぶるために, 図 4 の各曲がりダクトの $C_{p t i}$ から直線 ダクトの $C_{p t, i}$ の分布を入口境界位置での值を基淮に して差し引いた $\Delta C_{p h, i}$ を求め, その流路方向の分布を 図 5 に示す．本研究では「 $\Delta C_{p t, i}$ を流路渦に起因する 全圧損失」として定義した. 図 5 から CD入口付近を 境に， $\propto$ 増加により $\Delta C_{p h i}$ が増加することがわかる.

図6には二次流れの強さの指標として, 渦度の流路 方向成分 $\omega_{i}$ の絶対值の断面質量平均值 $\left|\omega_{i}\right|_{, i}$ の流路方 向分布を示寸. 図 7 に翼列の負荷分布に対応寸ると考 えられる,CD付近の内壁面近傍と外壁面近傍で $\mathrm{j}$ 方向に

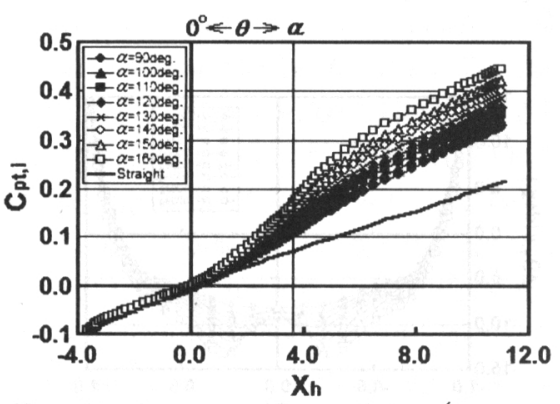

Fig.4 Total pressure loss coefficient $\left(L_{c}=\right.$ const. $)$

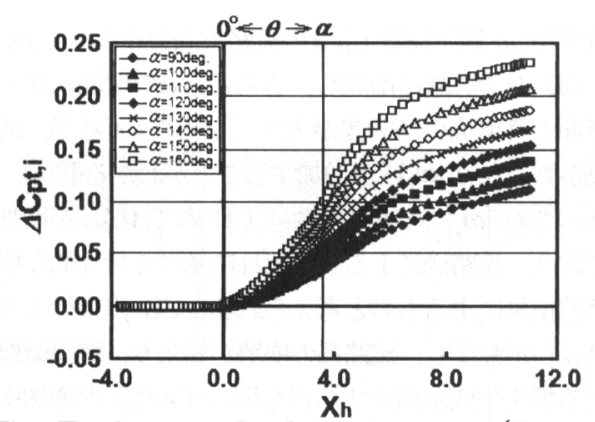

Fig.5 Total pressure loss by passage vortex $\left(L_{k}=\right.$ const. $)$ 


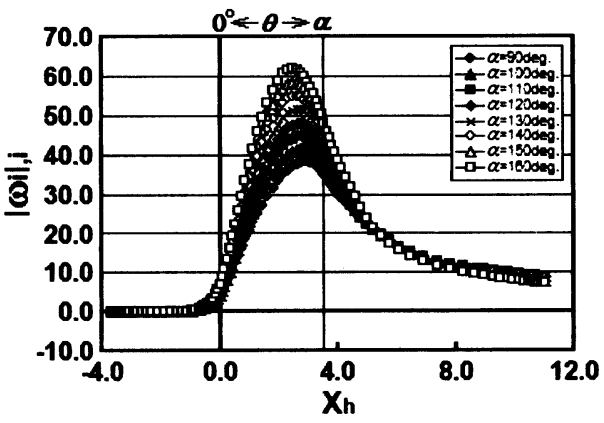

Fig.6 Component of vorticity in main flow direction $\left(L_{c}=\right.$ oonst. $)$

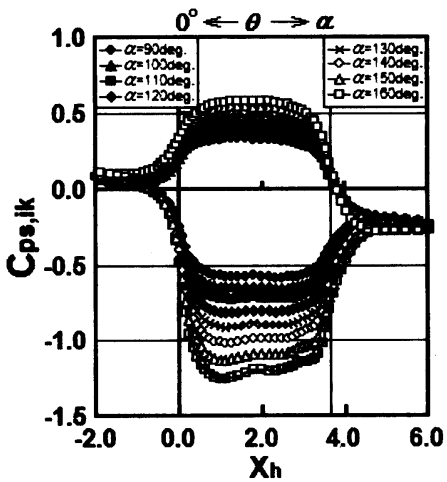

Fig.7 Static pressure coefficient $\left(L_{c}=\right.$ oonst. $)$

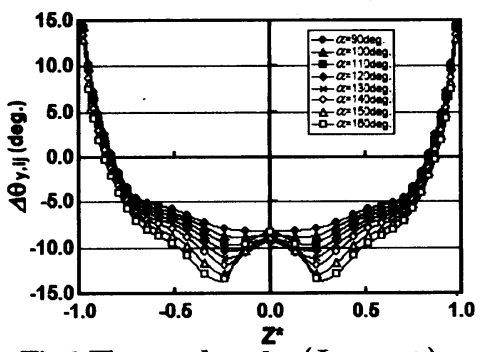

Fig. 8 Flow angle at $\theta=\alpha\left(L_{c}=\right.$ const. $)$

質量平均した静圧俰数 $C_{p,, i k}$ の流路方向分布を示す $\left|\omega_{i}\right|, i$ は，CD 内で急激に増加し，さらに， $\alpha$ の増加に伴い 内壁面と外壁面の圧力差が大きくなるため(図 7), 流 路渦が強くなり $\left|\omega_{i}\right|_{, i}$ が増加することがわかる(図6). また, この $\left|\omega_{i}\right|_{i}$ の増加と共に CD 内で $\Delta C_{p t, i}$ が増加 しており，流路渦による二次流れに基づく付加的な壁 面摩擦損失によるものと考えられる. CD 出口付近で は $\left|\omega_{i}\right|_{i}$ が減少し, 流路渦の崩壊が始まり, 壁面摩擦 による損失生成が減少するにも関らず $\Delta \boldsymbol{C}_{\boldsymbol{p}, \boldsymbol{i}}$ の増加率 が最も大きくなっており，それに対応して $\left|\omega_{i}\right|$, の減
少率が最も大きいことから，流路渦の崩壊に起因する 二次流れ運動エネルギーの消散による混合損失が増加 すると考えられる(8). 全体的に $\left|\omega_{i}\right|_{, i}$ の减少率と $\Delta C_{p t, i}$ の増加率がほぼ対応していることもわかる(図 5,6).

軸流タービン翼列の仕事に関する重要なパラメータ である翼列出口流出角に対応するパラメータとして $\mathrm{CD}$ 出口断面 $(\theta=\alpha)$ での流れ角 $\theta_{y}$ の $\alpha$ からの偏向の度 合いを示す $\Delta \theta_{y}\left(=\theta_{y}-\alpha\right)$ を定義し, その $\mathbf{k}$ 方向質量 平均值 $\Delta \theta_{y, i j}$ のダクト幅方向の分布を図 8 に示す. 流 れ角 $\theta_{y}$ の定義は図 2 に示寸. 図8の $z$ 忙 $S / 2$ で無次 元化したダクト幅方向の距離である. 図 8 から $\Delta \theta_{y, i j}$ に対する $\alpha$ の増加による影響は，管壁付近より管中央 $(Z ゙=0.0)$ 付近で大きく， $\alpha$ の増加により流れがアンダ 一ターン傾向になることを示している. また, $Z=0.0$ 近傍では $\alpha$ を大きすると, $\Delta \theta_{y, i j}$ の值が上昇し $\boldsymbol{Z}=0.0$ で極值をとる分布を示している. この原因に つては後述する.

$5.2 R_{\sigma}=1.0$ で $R_{c}$ を固定した坦合 断面アスペクト 比が $R_{a}=1.0$ のダクトに対して, 表 2 に示すように平 均曲率半径 $R_{c}$ を固定して曲がり角 $\alpha$ を $90^{\circ} \sim 160^{\circ}$ の 範囲で $10^{\circ}$ 毎に変化させて解析を行った. この場合 は $の$ の増加と共に $\iota_{\boldsymbol{c}}$ 落增加する。

図 9 に $C_{p t, i}$ の流路方向分布を示す．また, 同図に は曲がりダクトと同断面形状の直線ダクトの $C_{p t i}$ の 分布も実線で示す. 図 10 おび 11 には $\Delta C_{p t, i}$ と $\left|\omega_{i}\right|_{, i}$

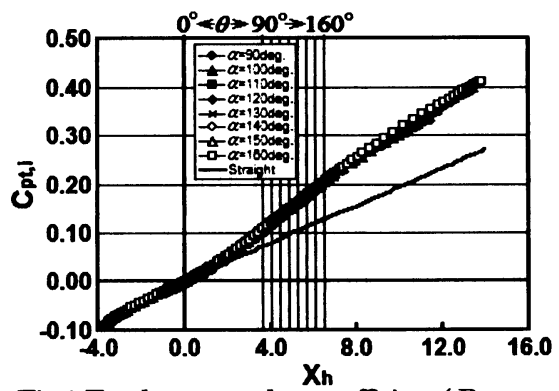

Fig.9 Total pressure loss coefficient $\left(R_{c}=\right.$ const. $)$

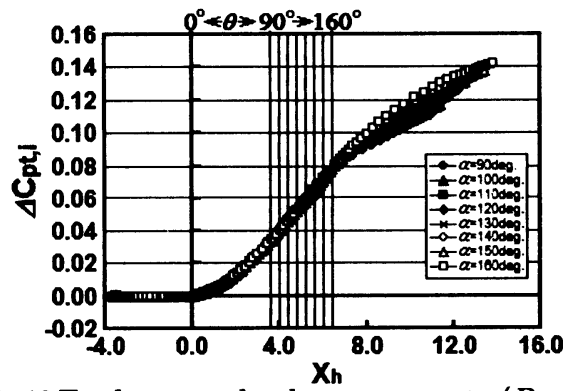

Fig.10 Total pressure loss by passage vortex $\left(R_{c}=\right.$ const. $)$ 


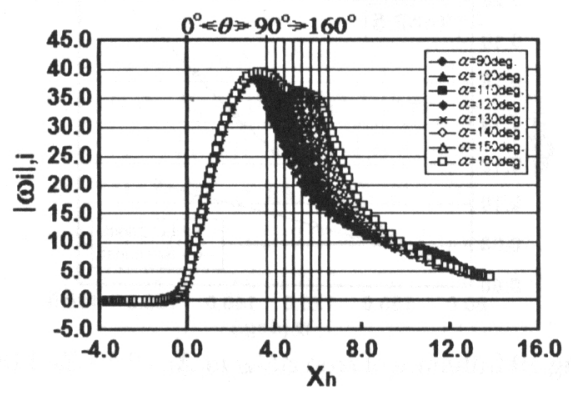

Fig.11 Component of vorticity in main flow direction $\left(R_{c}=\right.$ oonst. $)$

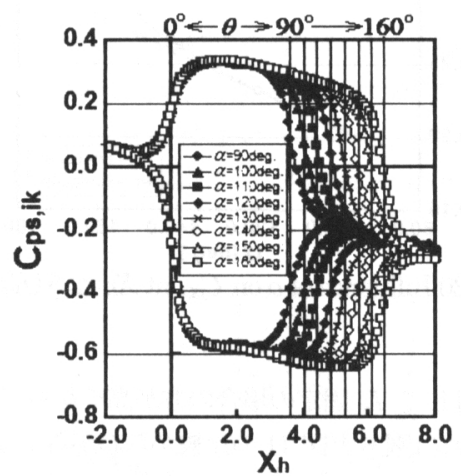

Fig.12 Static pressure coefficient $\left(R_{c}=\right.$ const. $)$

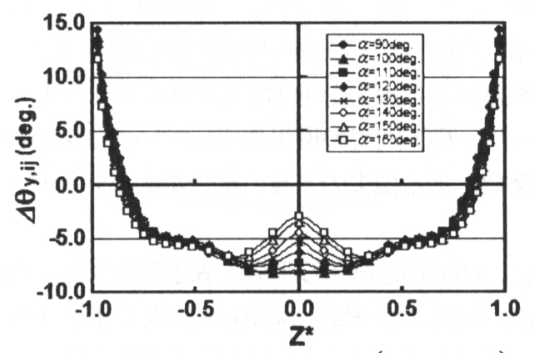

Fig.13 Flow angle at $\theta=\alpha\left(R_{c}=\right.$ const. $)$

の流路方向の分布をそれぞれ示寸. 図 12 には CD 付 近の内壁面近傍と外壁面近傍の $C_{p s, i k}$ の流路方向分布 を示す. 曲がりダクトの全圧損失 $C_{p t, i}$ 分布(図 9)は $\mathrm{CD}$ 入口 $\left(X_{h}=0.0\right)$ 付近から, 直線ダクトのものと差 を生じているが, 同じ管路長，すなわち，同じ $X_{h}$ の 位置における損失の大きさに対する $\alpha$ の増加による影 響は小さい，同様な傾向は $\Delta C_{p t, i}$ の分布(図 10)にも見 られる.これは流路渦の発達を示寸 $\left|\omega_{i}\right|$, 分布(図 11) の最大值が， $\alpha$ の増加に影響を受けないためである.

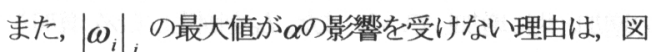
12 で示寸ように, 内壁面と外壁面の圧力差が $\alpha$ の増加 にほとんど影響を受けず，流路渦の強さに差が生じな いためである. また, 図 11 と図 12 の比較から, 各 $\alpha$ のダクトに対して CD 出口までほぼ一定の内外壁面間 圧力差が保たれるため, 流路渦も多少の崩壊を伴いな がらも CD 出口までその強さが維持されていることが わかる.

図 13 に CD 出口断面 $(\theta=\alpha)$ での $\Delta \theta_{y, i j}$ のダクト幅方 向の分布を示寸. $L_{c}$ 固定の場合(図 8)と比べると曲が り角 $\alpha$ の増加による，管中央付近の流れのアンダータ ーンの強さへの影響はほとんど無く, これは流路渦の 強さが $R_{c}$ 固定の場合は $\alpha$ の影響を受けないことに起 因する(図 11). しかし， $L_{c}$ 固定の場合と同様 $\alpha$ を大き く寸ると $Z ゙=0.0$ 近傍で $\Delta \theta_{y, i j}$ の值が上昇している. 図 14 には $\alpha=90^{\circ}$ の基淮モデルおよび $L_{c}$ 固定と $R_{c}$ 固定 の $\alpha=160^{\circ}$ の場合の CD 出口断面における二次流九速 度べクトルとその流線図を流九の対称性を考慮してそ れぞれ対称面から半分を示寸. 図 15 には図 14 と同断 面での全圧損失係数 $C_{p t}$ 分布を示寸. これらの図にお いて, $\alpha=90^{\circ}$ の基準モデルに対して,$L_{c}$ または $R_{c}$ 固定のもとに $\alpha$ 増加させると, CD 出口断面内の内 壁面中央付近の破線で囲んだ高損失領域が拡大し(図 15)，その領域によって一対の流路渦が分離されるが (図 14)，その領域内で流路渦と逆回転の一対の渦の発 生の兆候が見られ， $R_{c}$ 固定の場合の $\alpha=160^{\circ}$ ではそ の発生が確認できる(図 14(c)). したがって, 図8およ

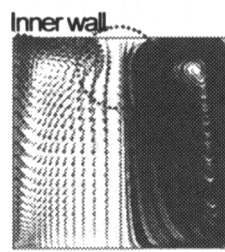

(a) $\alpha=90 \mathrm{deg}$.

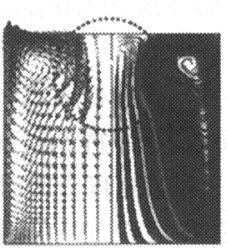

(b) $\alpha=160 \mathrm{deg}$. ( $L_{k}=$ oonst.)

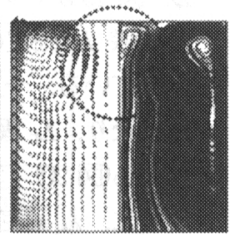

(c) $\alpha=160 \mathrm{deg}$. ( $R_{c}=$ const. $)$

Fig.14 Secondary flow velocity vectors and streamlines at exit of CD

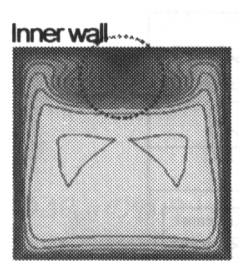

(a) $\alpha=90 \mathrm{deg}$.

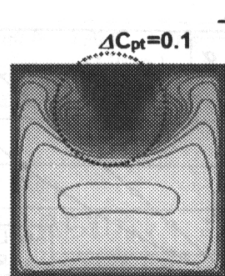

(b) $\alpha=160 \mathrm{deg}$. ( $L_{c}=$ oonst.)

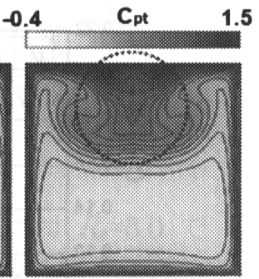

(c) $\alpha=160 \mathrm{deg}$. ( $R_{c}=$ const.)

Fig.15 Total pressure loss distribution at exit of CD 
ひ図 13 で見られた $z=0.0$ 近傍の $の$ 増加による $\Delta \theta_{y, i j}$ の值の上昇は，この高損失領域内での流路渦と逆回転 の渦の発生により対称面近傍で内壁へ向う流れが生じ るためと考えられる.

$5.3 R_{a}=1.0$ の㙂合の $R_{c}$ 固定と $L_{c}$ 固定の比較 図 16 に，図 $7\left(L_{c}=\right.$ const $)$ と図 $12\left(R_{c}=\right.$ const $)$ に示されている内外

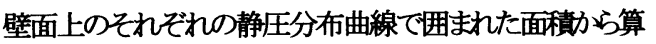
出された, $\mathrm{CD}$ 内C゙の内外壁間の圧力差 $A_{c p s}$ の $\alpha$ に対す る変化を示す.タービン翼の翼負荷に対応する $A_{c p s}$ は $\alpha$ の増加と共に増加ててる. また， $L c$ を固定して $\alpha$ を増加さ せた方が $A_{c p s}$ が高い 值を示している.

$\mathrm{CD}$ 内C゙の $L_{c}$ 固定と $R_{c}$ 固定の場合の損失増加の違い を調いるために図 17 およひ雨 18 にCD 出口 $(\theta=\alpha)$ に おける $\Delta C_{p t, i}$ と $C_{p t i}$ の $\alpha$ に対する変化をそれぞれ示す. 流路渦に起因する損失 $\Delta C_{p t, i}$ は $\alpha$ 大゙大きくなると, 同

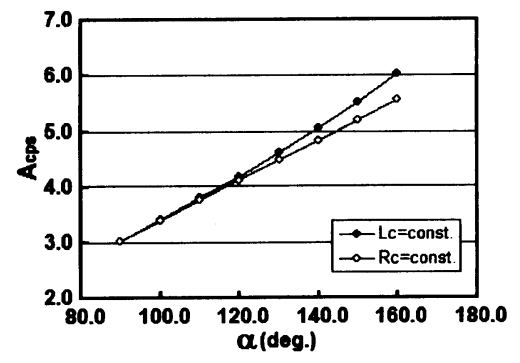

Fig.16 Influence of $\alpha$ on pressure difference $A_{q p s}\left(R_{a}=1.0\right)$

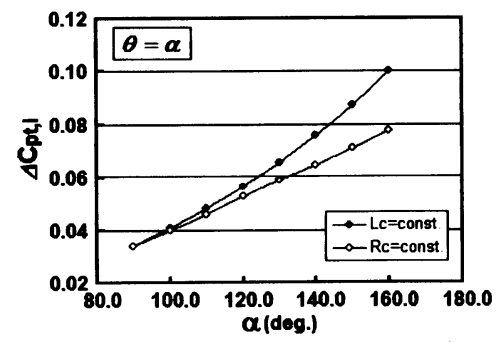

Fig.17 Influence of $\alpha$ on $\Delta C_{p, i}$ at $\theta=\alpha\left(R_{\theta}=1.0\right)$

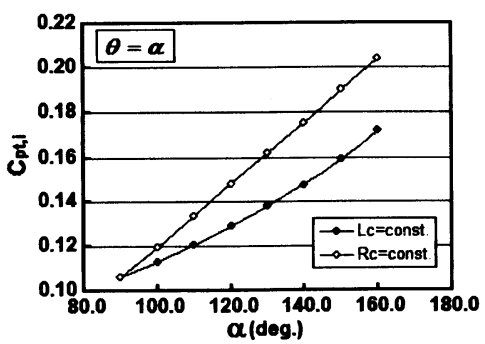

Fig.18 Influence of $\alpha$ on $C_{p t i}$ at $\theta=\alpha\left(R_{a}=1.0\right)$

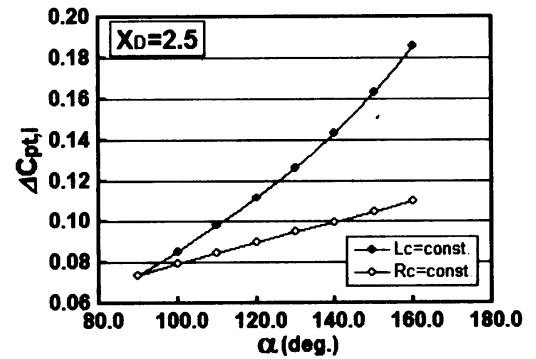

Fig.19 Influence of $\alpha$ on $\Delta C_{p t ;}$ at $X_{D}=2.5\left(R_{R}=1.0\right)$

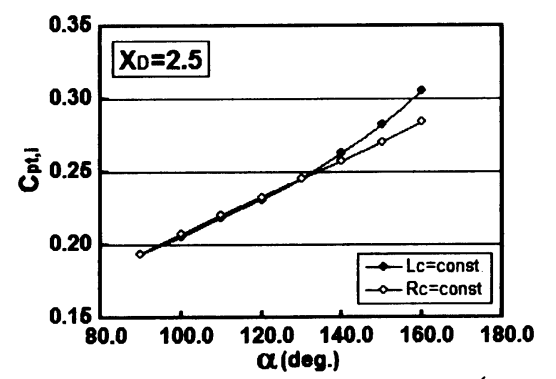

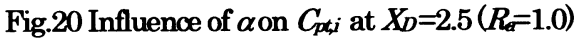

じ $\alpha に$ 対して $L_{c}$ 固定の場合の方が高くなっている(図 17).これは図 6 と図 11 の比較からわかるように，同 じ $\alpha$ に対して $L_{c}$ 固定の場合の方が，流路渦がより強 くなることに起因している. 一方, 全圧損失 $C_{p t i}$ は 同じ $\alpha$ に対して $R_{c}$ 固定の場合の方が高くなっている (図 18). これは同じ $\alpha$ に対して $R_{c}$ 固定の方が $L_{c}$ が長 くなるため(表 2),CD内の壁面の総面積は大きくなり， 壁面摩擦による損失が増加するためと考えられる. し たがって, CD 内での損失生成においては流路渦より 壁面摩擦による損失の寄与の割合が大きいと考えられ る.

次に, CD 下流での $L_{c}$ 固定と $R_{c}$ 固定の場合の損失増 加の違いを調いるために，図 19 およひ図 20 に CD 出口 から下流 $X_{D=2.5}$ における $\Delta C_{p, i}$ と $C_{p t, i}$ の $\alpha$ に対する 変化をそれぞれ示す。ここで $X_{D}$ は $\mathrm{CD}$ 出口 $(\theta=\alpha)$ を 原点とする $L_{R}$ で無次元化した流路方向距離である図

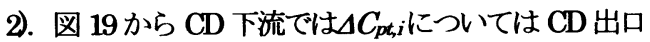
と同様 $L_{\boldsymbol{c}}$ 固定の場合の方が $\boldsymbol{\alpha}$ の増大と共に高い値を 示している. 一方, $C_{p t, i}$ については CD 出口図 18)と

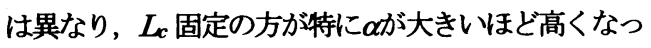
ている(図 20).これは図 17 と図 19 の比較からわかる ように, $L_{c}$ 固定の場合の方が $\mathrm{CD}$ 出口 $(\theta=\alpha)$ から下流 $\left(X_{D}=2.5\right)$ にかけての $\Delta C_{p t ;}$ の増加が $\alpha$ の増加と共に大 きくなっていることに起因しており，したがって， 
CD 下流での損失生成においては流路渦の崩壊による 損失の寄与の割合が大きくなると考えられる.

$5.4 R_{a}=1.0$ と $R_{a}=3.0$ の封合の比较 断面アスペク 比 $R_{a}=3.0$ のダク外に対して, $R_{a}=1.0$ と同様に $L_{c}$ 固定ま たは $R_{c}$ 固定で $\alpha$ を $90^{\circ} \sim 160^{\circ}$ の範囲で $10^{\circ}$ 毎に変化 させて解析を行った. $R_{a}=3.0$ の場合も全圧損失 $C_{p t, i}$ 分布, 流路渦に起因する全圧損失 $\Delta C_{p t, i}$ 分布, 渦度の主 流方向成分の絶対值 $\left|\omega_{i}\right|_{,}$分布および CD 付近の内外 壁面上の $C_{p s, i k}$ の分布は曲がり角 $\alpha$ の変化に対して $R_{a}=1.0$ の場合と定性的に同し傾向を示した 図 21 に $L_{c}$ 固定と $R_{c}$ 固定の場合の CD 出口断面 $(\theta=\alpha)$ での $\Delta \theta_{y}$ の $\mathrm{k}$ 方向質量平均値 $\Delta \theta_{y, i j}$ のダクト幅 $Z \mathbf{Z}$ 方向の分布を示 す. $\Delta \theta_{y, i j}$ に関しても $R_{a}=1.0$ の場合と同様に $L_{c}$ 固定 の場合はのの増加により管中央付近の $\Delta \theta_{y, j}$ が減少しア ンダーターン傾向は強くなるが, $\boldsymbol{R}_{c}$ 固定の場合は $の$ 影響はほとんど見られない. しかし， $R_{\approx}=1.0$ (図 8,13)で見られた のの増加による対称面 $(Z ゙=0.0)$ 近傍で

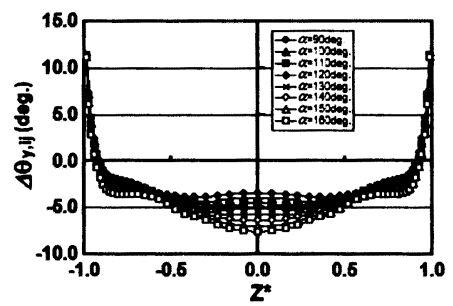

(a) $L_{c}=$ const.

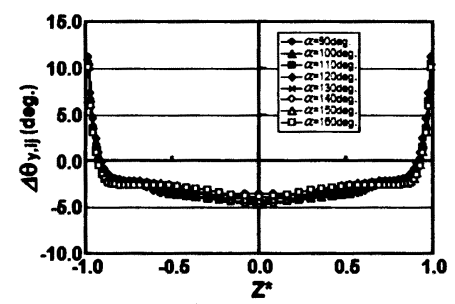

(b) $R_{c}=$ const.

Fig.21 Flow angle at $\theta=\alpha\left(R_{a}=3.0\right)$

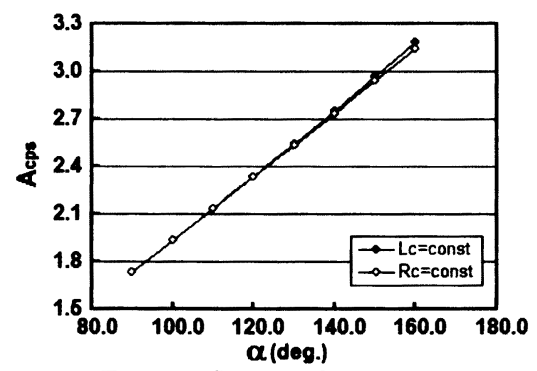

Fig.22 Influence of $\alpha$ on pressure difference $A_{q p s}\left(R_{a}=3.0\right)$

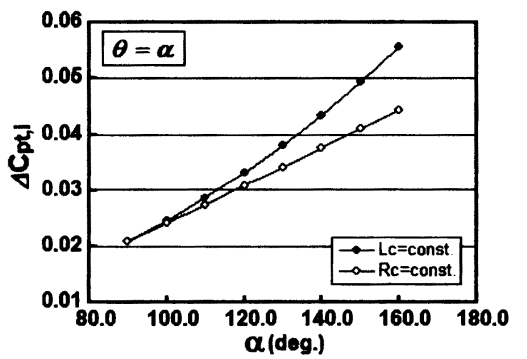

Fig.23 Influence of $\alpha$ on $\Delta C_{p t i}$ at $\theta=\alpha\left(R_{e}=3.0\right)$

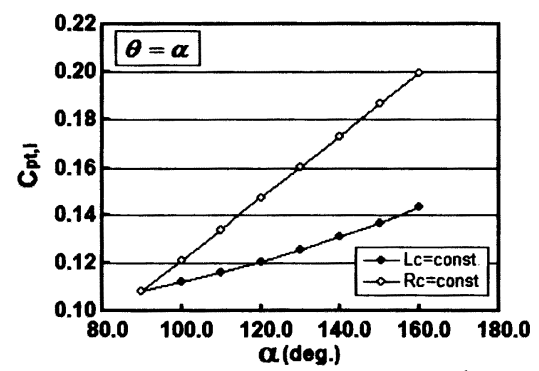

Fig.24 Influence of $\alpha$ on $C_{p t i}$ at $\theta=\alpha\left(R_{a}=3.0\right)$

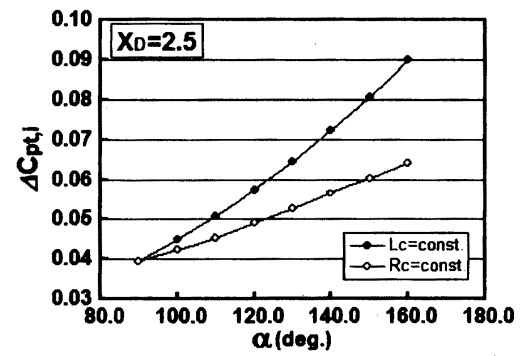

Fig.25 Influence of $\alpha$ on $\Delta C_{p t i}$ at $X_{D}=2.5\left(R_{a}=3.0\right)$

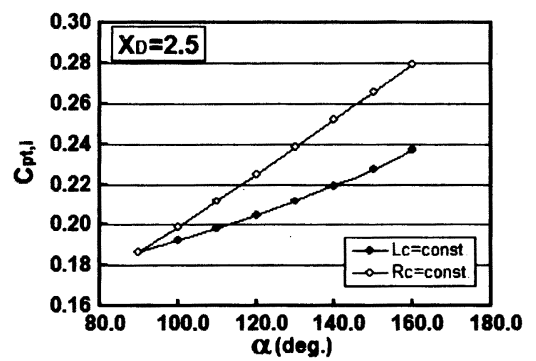

Fig.26 Influence of $\alpha$ on $C_{p t i}$ at $X_{D}=2.5\left(R_{a}=3.0\right)$

の $\Delta \theta_{y, i j}$ の値の上昇は見られない.これは $R_{a}=3.0$ で は $R_{a}=1.0$ に比べて流路渦同士の干涉力゙弱いため(2), 対称面近傍で流路渦と逆回転の渦が生じないためと考 えられる。 
図22に，CD内での内外壁間圧力差 $A_{c p s}$ の $\alpha$ に対す る変化を示寸. $R_{a}=1.0$ の場合と同様に $の$ 増加と共に $L_{c}$ 固定の場合も $R_{c}$ 固定の場合も $A_{c p s}$ は増加するが, その増加割合はほぼ同じである。

図 23 およひ図 24 に CD 出口における $\Delta C_{p t, i}$ と $C_{p t, i}$ の风に対する変化をそれぞれ示す. 図 25 およひ図 26 には CD 出口から下流 $X_{D}=2.5$ における $\Delta C_{p t, i}$ と $C_{p t i}$ の $\alpha$ に対する変化をそれぞれ示す. CD 出口では $R_{a}=1.0$ の場合(図 17)と同様に, 同じ $\alpha$ に対して $L_{c}$ 固 定の場合の方が流路渦に起因する全圧損失 $\Delta C_{p t, i}$ は高 くなっている(図 23). これは先にも述べたように, 同 じ $\alpha$ 対して $L_{c}$ 固定の場合の方が流路渦が強いため と考えられる. また，全圧損失 $C_{p t, i}$ に関しても(図 24$)$, $R_{c}$ 固定の方が壁面摩擦による損失が大きくなるため 同じ $\ltimes$ に対して高くなっており， $R_{a}=1.0$ の場合(図 18) と同様な傾向を示している. 一方, CD 下流では流路

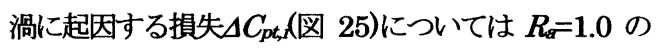
場合(図 19) と同様に $L_{c}$ 固定の場合の方が $の$ 増大と共 に高い值を示しているが, 全圧損失 $C_{p t, i}$ (図 26)につ いては $R_{a}=1.0$ の場合(図 20) と異なり, $\mathrm{CD}$ 出口と同 様に $\alpha$ 増加により $R_{c}$ 固定の方が高くなっている. この原因は $R_{a}=1.0$ の場合に述べたように, CD 下流 の損失生成においては壁面摩損失以外に CD 内で発 達した流路渦の崩壊による損失の寄与が増加する. し かし, $R_{\mathbb{a}}=1.0$ に比べて $R_{\mathbb{a}}=3.0$ の場合の CD 内での 流路渦の発達は弱く(2), 図 23 と図 25 の比較からわか るように CD 下流でのその崩壊に伴う損失増加が $R_{a}=1.0$ の場合(図 17,19)に比べて小さいためと考え られる. 以上の結果および第 2 報(2)の結果から, 曲が り角 $\alpha$ を増加させた場合, 流路渦に起因する損失生成 が急激に増加する $R_{a}=2.0$ 以下の断面アスペクト比を 有する曲がりダクトにおいては, $R_{c}$ 固定の方が損失 壃加は抑えられるが, $L_{\boldsymbol{c}}$ 固定の方が $A_{c p s}$ は増加する. 一方, $R_{a}=2.0$ 以上の曲がりダクトにおいては, $L_{c}$ 固 定の方が $R_{c}$ 固定より損失堌加を抑えたまま $A_{c p s}$ を増 加させることができる.

以上の静止曲がりダクトに対する結果から, 翼間流 路断面アスペクト比を比較的大きくし, 流路渦同士の 干涉を低减させた軸流タービン翼列では，翼面積の増 加を抑えて転向角を増加させた方が，損失の増加を抑 えたままで翼負荷を増加できることがわかる。

\section{6. 結 䛿}

曲がりダクト内の流れを, 2 種類の断面アスペクト 比を有する曲がりダクトに対して, 湾曲部長さまたは
平均曲率半径を固定し，曲がり角を変化させて解析す ることにより以下の結論を得た.

（1）曲がり角を增加させると, 湾曲部長さを固定した 場合, 平均曲率半径の堿少により, 内外壁間の圧力差 が増加し流路渦が強くなるため, その崩壊に伴う損失 増叻が, 一方, 平均曲率半径を固定した場合, 流路渦 の増強は無いため, 湾曲部流路長さの延長に伴う壁面 摩擦による損失増加が，全体の損失の生成に強く影響 を与える.

(2) 曲がり角を増加させると, 湾曲部長さ固定の場合 は流路渦が強くなるために, 湾曲部出口流出角が減少 するが, 平均曲率半径を固定した場合は流路渦の強さ の変化が小さいため流出角の変化も小さい．

(3) 損失生成の中で流路渦に起因する損失生成の割合 が大きい断面アスペクト比の曲がりダクトに対して曲 がり角を増加させた場合, 平均曲率半径固定の方が損 失増加は抑えられるが, 湾曲部長さ固定の方が内外 壁間圧力差は増加する.

(4) 損失生成の中で流路渦に起因する損失生成が小さ い断面アスペクト比の曲がりダクトに対して曲がり角 を増加させた場合, 湾曲部長さ固定の方が損失増加を 抑えたまま内外壁間圧力差を増加させることができ る.

(5) 翼間流路断面アスペクト比を比較的大きくし，流 路渦同士の干涉を低減させた軸流タービン翼列では, 翼面積の増加を抑えて転向角を増加させた方が，損失 の増加を抑えたままで翼負荷を増加させることができ る.

\section{文献}

（1）辻田星歩・石田泰大 ・水木新平・山本孝正, 曲がりダクト によるターボ機械内部流九の損失生成桡椿の解明（第 1 報，

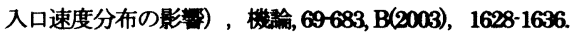

（2）辻田星歩・水木新平・山本孝正，曲がりダクトによるター ボ機械内部流九の損失生成機椿の解明（第 2 報, 断面アス ペクト比の影䱥)，機論, 70694, B(2004), 1496-1503.

(3) Yamamoto, A and Outa, E,"'Tow-Speed Annular Cascade Tests of an Ultra-Highly Loeded Turbine with Trp Clearanoe, Part 1-Near Design Incidence," ASME Paper 99GT-212( 1999).

(4) Yamamota, A, Usui, H, Mizuki, S, Tsü̈ta, H, Outa, E, Research of Ultra-Highly Loaded Turbines, Proc. The 1* International Symposium of Environmentally Compatible Propulsion Transport, C-9(2002).

（5）辻田星歩・水木新平・山本孝正, 超高負荷タービン翼列内 の流れの数值解析, 機論, 70697, B(2004), 2332-2340.

（6）辻田星歩・水木新平，境界適合座標系上の物理成分テンソ ル形運動方程式を用いた曲がり管内の粘性流の数值解析, 機部, 57-540, B(1991), 2606-2613.

（7）辻田星歩・水木新平, 圧力補正法を用いた圧綰性流九の数 值解析, 機論, 63608, B(1997), 1270-1278.

(8) Moore, J. and Adhye, R. Y, Secondary Flows and Looses Downstream of a Turtine Cascade, Trans. ASME J. Eng. Power, 107-10(1985), 961-968. 